Gazi University
Journal of Science
http://dergipark.gov.tr/gujs

\title{
Expired Abacavir Sulfate Drug as Non-toxic Corrosion Inhibitor for Mild Steel (MS) in 3 M Hydrochloric Acid System
}

\author{
Narasimha RAGHAVENDRA ${ }^{1, *}$ \\ ${ }^{I}$ Department of Chemistry, K.L.E. society's P. C. Jabin Science College (Autonomous) Vidyanagar, Hubballi-580031 \\ Highlights \\ - The present paper mainly focused on solution for corrosion problem in several sections. \\ - Tafel plot and impedance study confirms the mixed corrosion inhibition property of expired Abacavir Sulfate drug. \\ - Mixed MS corrosion inhibition property of expired Abacavir Sulfate drug was confirmed by Tafel plot studies.
}

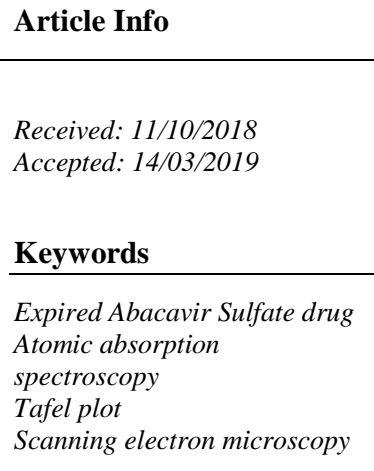

\section{INTRODUCTION}

The study of mild steel (MS) corrosion is very much important due to indirect and direct losses generated by scourge. Hydrochloric acid solutions are generally employed for cleaning, elimination of dust deposits, stimulation of oil wells. Corrosion is an electrochemical process which disintegrates the MS metal. This is a major issue to be addressed by educational and industrial sectors [1-4]. This is because; it causes huge economic losses across the world. Among the numerous corrosion control techniques, use of corrosion inhibitors is the cost effective and most popular approach of MS corrosion control because of high efficiency, facile feasibility and economic synthesis. The inhibitor creates an invisible protective layer on the MS that isolates MS from the aggressive $\mathrm{HCl}$ solution and inhibit the disintegration process [5-7]. The inhibition (protection) ability and high adsorption of the organic compound is lying on the fact that, organic species easily transfer electrons to the MS surface. Organic species with $\mathrm{N}, \mathrm{O}, \mathrm{S}$ and $\mathrm{P}$ elements are considered to be effective adsorption centers. Even though use of organic species as corrosion inhibitors is one of the economic, effective and easiest_methods. But, due to increasing in the awareness of environmental chemistry in the corrosion science field, there is need to discover the green corrosion inhibitors [8-10]. Environmental chemistry is a vital principle which effectively reduces the use of toxic species in design and manufacture application. Hence, the present focus is towards expired drug products. These expired drug products are non toxic and proficient of ensuring robust protection of MS. Hence, in present research, the expired Abacavir Sulfate drug is selected and studied MS corrosion inhibition property 
by weight loss, Tafel plot, atomic absorption and impedance spectroscopy techniques. Surface studies were carried out by scanning electron microscopy (SEM) technique.

\section{EXPERIMENTAL STUDIES}

\subsection{Preparation of Nontoxic Corrosion Inhibitor and 3 M HCl Solution}

Expired Abacavir Sulfate drug collected and different concentrations namely $0.1 \mathrm{~g} / \mathrm{L}, 0.2 \mathrm{~g} / \mathrm{L}, 0.3 \mathrm{~g} / \mathrm{L}$ and $0.4 \mathrm{~g} / \mathrm{L}$ were prepared by using the double distilled water. $3 \mathrm{M} \mathrm{HCl}$ solutions was prepared according to the standard procedure.

\subsection{Mild Steel (MS) Preparation}

$99 \%$ of MS specimen having the rectangular shapes with $5 \mathrm{~cm} \times 2 \mathrm{~cm} \times 0.3 \mathrm{~cm}$. Before performing the MS corrosion test, MS polished with 1000 and 2000 grades of sand papers. The MS is thoroughly washed with double distilled water and acetone.

\subsection{Gravimetric Measurement}

MS immersed in $100 \mathrm{ml}$ of $3 \mathrm{M} \mathrm{HCl}$ solution without and with $0.1 \mathrm{~g} / \mathrm{L}, 0.2 \mathrm{~g} / \mathrm{L}, 0.3 \mathrm{~g} / \mathrm{L}$ and $0.4 \mathrm{~g} / \mathrm{L}$ of expired Abacavir Sulfate drug at $60{ }^{\circ} \mathrm{C}$ with an immersion period of 3, 6, 9, 12 and 15 hours. Gravimetric studies repeated and average values are reported. The protection efficiency of expired Abacavir Sulfate drug is calculated from the below relation,

Protection efficiency $(\%)=\frac{\left(\mathrm{W}_{1}-\mathrm{W}_{2}\right)}{\mathrm{W}_{1}} \times 100$

where, $\mathrm{W}_{1}=$ Weight loss of MS in free $3 \mathrm{M} \mathrm{HCl}$ solution and $\mathrm{W}_{2}=$ Weight loss of $\mathrm{MS}$ in protected $3 \mathrm{M} \mathrm{HCl}$ solution.

\subsection{Atomic Absorption Spectroscopy (AAS)}

The AAS technique utilized in order to find out the amount of dissolved iron content of mild steel in $3 \mathrm{M}$ $\mathrm{HCl}$ solution without and with four different amounts of expired Abacavir Sulfate drug (i.e. $0.1 \mathrm{~g} / \mathrm{L}, 0.2$ $\mathrm{g} / \mathrm{L}, 0.3 \mathrm{~g} / \mathrm{L}$ and $0.4 \mathrm{~g} / \mathrm{L})$.

The corrosion protection efficiency can be find out by following relation,

$$
\text { Corrosion protection efficiency }=\frac{B-A}{B} \times 100,
$$

where, $\mathrm{B}=$ Dissolved iron content in uninhibited solution and $\mathrm{A}=$ Dissolved iron content in inhibited solution.

\subsection{Electrochemical Studies}

Electrochemical studies (both Tafel plot and impedance spectroscopy) studies were carried out with the help of CHI workstation. The MS as working electrode, platinum cell as counter electrode and saturated calomel cell as standard electrode. Open circuit potential obtained by submerging the MS in $3 \mathrm{M} \mathrm{HCl}$ solution for about 90 minutes. Nyquist plots obtained by applying the frequency in the range of $100 \mathrm{kHz}$ to $10 \mathrm{MHz}$ with a scan rate of $0.1 \mathrm{mV} / \mathrm{s}$. The Tafel plots are recorded in the frequency range of $-250 \mathrm{mV}$ to $+250 \mathrm{mV}$ with a scan rate of $0.1 \mathrm{mV} / \mathrm{s}$.

With the help of Tafel plots, the corrosion protection efficiency can be calculated from the equation below, 


$$
\text { Protection efficiency }=\left[1-\frac{i_{\text {corr }}^{\prime}}{i_{\text {corr }}}\right] \times 100
$$

where, $i^{\prime}$ corr $=$ Protected MS corrosion current density and $i_{\text {corr }}=$ Unprotected corrosion current density.

The charge transfer resistance $\left(R_{c t}\right)$ values are used in the calculation of protection efficiency of the expired Abacavir Sulfate drug as per the following equation,

$$
\text { Protection efficiency }=\frac{\mathrm{R}_{\mathrm{ct}(\mathrm{inh})}-\mathrm{R}_{\mathrm{ct}}}{\mathrm{R}_{\mathrm{ct}(\mathrm{inh})}} \times 100
$$

where, $\mathrm{R}_{\mathrm{ct}}=$ Unprotected charge transfer resistance value and $\mathrm{R}_{\mathrm{ct}(\mathrm{inh})}=$ Protected charge transfer resistance value.

\subsection{Scanning Electron Microscopy Technique}

MS surface morphology without and with expired Abacavir Sulfate drug was examined by scanning electron microscopy with an immersion period of 2 hours.

\section{RESULTS AND DISCUSSION}

\subsection{Weight Loss Studies}

The effect of contact time on the corrosion inhibition efficiency of the MS in $3 \mathrm{M} \mathrm{HCl}$ solution was studied by weight loss technique at $60^{\circ} \mathrm{C}$ with four different amounts of expired Abacavir Sulfate drug. Table 1 shows the corrosion protection efficiency of the expired Abacavir Sulfate drug for MS in $3 \mathrm{M} \mathrm{HCl}$ solution without and with $0.1 \mathrm{~g} / \mathrm{L}, 0.2 \mathrm{~g} / \mathrm{L}, 0.3 \mathrm{~g} / \mathrm{L}$ and $0.4 \mathrm{~g} / \mathrm{L}$ of expired Abacavir Sulfate drug. The protection efficiency of the expired Abacavir Sulfate drug enhances with a rise in the expired Abacavir Sulfate drug amounts. This can be explained by adsorption of expired Abacavir Sulfate drug molecules on the MS in 3 $\mathrm{M} \mathrm{HCl}$ solution. The physical/chemical attraction between the expired Abacavir Sulfate drug and MS in 3 $\mathrm{M} \mathrm{HCl}$ solution reduces the corrosion rate of the MS in $3 \mathrm{M} \mathrm{HCl}$ solution. The attraction between the expired Abacavir Sulfate drug and MS in $3 \mathrm{M} \mathrm{HCl}$ solution increases with a rise in the expired Abacavir Sulfate drug concentration. It is also observed that, the increase in the immersion period from 3 hours to 15 hours reduces the MS corrosion protection property of expired Abacavir Sulfate drug in the 3 $\mathrm{M} \mathrm{HCl}$ solution. The increase in the contact time from 3 hours to 15 hours facilitates the desorption phenomena of chemically/physically adsorbed expired Abacavir Sulfate drug species in the $3 \mathrm{M} \mathrm{HCl}$ solution. At higher immersion period, the protection rate is slightly lower; this is because of increase in the acceleration of the mild steel corrosion process which is due to the formation of unstable protective layer of expired Abacavir Sulfate drug on the MS surface in the $3 \mathrm{M} \mathrm{HCl}$ solution at higher immersion period.

Table 1. Weight loss results for mild steel in $3 \mathrm{M} \mathrm{HCl}$ solution without and with corrosion inhibitor

\begin{tabular}{|c|c|c|}
\hline $\begin{array}{c}\text { Concentration } \\
(\mathrm{g} / \mathrm{L})\end{array}$ & $\begin{array}{c}\text { Immersion } \\
\text { period }\end{array}$ & $\begin{array}{c}\text { Protection } \\
\text { efficiency (in } \\
\text { percentage) }\end{array}$ \\
\hline Blank & 3 & 70.000 \\
0.1 & & 80.000 \\
0.2 & & 85.000 \\
0.3 & & 95.000 \\
0.4 & 6 & 74.285 \\
Blank & & 82.857 \\
0.1 & & 88.571 \\
0.2 & & 94.285 \\
0.3 & & 78.688 \\
0.4 & 9 & \\
Blank & & \\
0.1 & & \\
\hline
\end{tabular}




\begin{tabular}{|c|c|c|}
\hline 0.2 & & 85.245 \\
0.3 & & 86.885 \\
0.4 & & 88.524 \\
Blank & 12 & 74.444 \\
0.1 & & 76.666 \\
0.2 & & 78.888 \\
0.3 & & 83.333 \\
0.4 & & 73.636 \\
Blank & 15 & 77.272 \\
0.1 & & 80.909 \\
0.2 & & 85.454 \\
0.3 & & \\
0.4 & & \\
\hline
\end{tabular}

\subsection{Atomic Absorption Spectroscopy (AAS) Technique}

The AAS technique used in order to examine the weight of dissolved iron content of the MS in the $3 \mathrm{M}$ $\mathrm{HCl}$ solution without and with $0.1 \mathrm{~g} / \mathrm{L}, 0.2 \mathrm{~g} / \mathrm{L}, 0.3 \mathrm{~g} / \mathrm{L}$ and $0.4 \mathrm{~g} / \mathrm{L}$ of expired Abacavir Sulfate drug. The results of AAS are shown in the Table 2 and Figure 1. The atomic absorption spectroscopy studies show that, the weight of dissolved iron content is low in the presence of four different amounts of expired Abacavir Sulfate drug on the MS in $3 \mathrm{M} \mathrm{HCl}$ solution, whereas, in the absence of expired Abacavir Sulfate drug, the weight of dissolved iron content is high in the free $3 \mathrm{M} \mathrm{HCl}$ solution. These differences are a clear hint of corrosion protection property of expired Abacavir Sulfate drug on the MS in $3 \mathrm{M} \mathrm{HCl}$ solution. Presence of expired Abacavir Sulfate drug on the surface of MS in $3 \mathrm{M} \mathrm{HCl}$ solution prevents the loss of iron content of $\mathrm{MS}$ in $3 \mathrm{M} \mathrm{HCl}$ solution.

Table 2. Atomic absorption spectroscopy results for mild steel metal in $3 \mathrm{M} \mathrm{HCl}$ solution

\begin{tabular}{|c|l|l|}
\hline $\begin{array}{l}\text { Concentration } \\
(\mathrm{g} / \mathrm{L})\end{array}$ & $\begin{array}{l}\text { Amount of } \\
\text { MS } \\
\text { dissolved in 3 } \\
\text { M HCl } \\
\text { solution }\end{array}$ & $\begin{array}{l}\text { Protection } \\
\text { efficiency } \\
\text { percentage) }\end{array}$ \\
\hline Blank & 0.050 & \\
0.1 & 0.010 & \\
0.2 & 0.0048 & 80.000 \\
0.3 & 0.0043 & 90.400 \\
0.4 & 0.0030 & 91.400 \\
& & 94.000 \\
& & \\
\hline
\end{tabular}




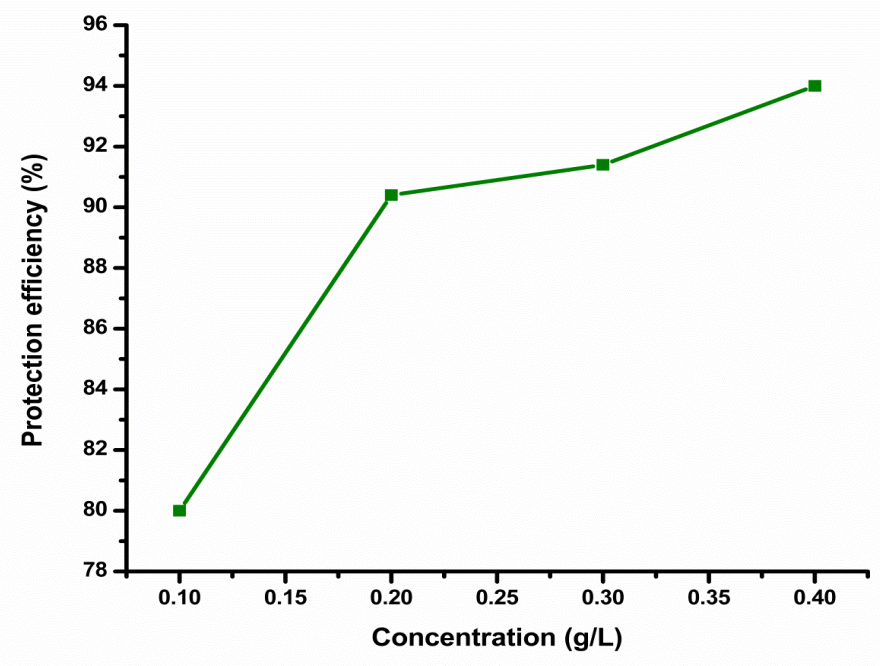

Figure 1. Atomic absorption spectroscopy results

\subsection{Electrochemical Studies}

\section{Tafel plot studies}

The cathodic and anodic Tafel plots for MS in $3 \mathrm{M} \mathrm{HCl}$ solution without and with $0.1 \mathrm{~g} / \mathrm{L}, 0.2 \mathrm{~g} / \mathrm{L}, 0.3 \mathrm{~g} / \mathrm{L}$ and $0.4 \mathrm{~g} / \mathrm{L}$ of expired Abacavir Sulfate drug are shown in the Figure 2. The Tafel plot parameters such as corrosion potential $\left(\mathrm{E}_{\text {corr }}\right)$, corrosion current density ( $\mathrm{i}$ corr), cathodic Tafel coefficient $(\beta \mathrm{c})$, anodic Tafel coefficient $(\beta a)$ and protection efficiency of the expired Abacavir Sulfate drug as shown in the Table 3. The

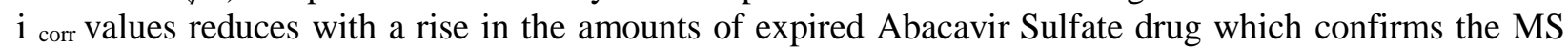
corrosion protection property of expired Abacavir Sulfate drug in the $3 \mathrm{M} \mathrm{HCl}$ solution. The decrease in the corrosion current density values enhances the corrosion inhibition property on the surface of MS in an acidic environment. The expired Abacavir Sulfate drug causes no change in the cathodic, anodic Tafel coefficients and corrosion potential values. This shows the MS mixed corrosion inhibition property of expired Abacavir Sulfate drug in the $3 \mathrm{M} \mathrm{HCl}$ solution. The expired Abacavir Sulfate drug controls the both cathodic and anodic MS corrosion reaction in the $3 \mathrm{M} \mathrm{HCl}$ solution.

Table 3. Tafel plot results of mild steel in $3 \mathrm{M} \mathrm{HCl}$ solution without and with corrosion inhibitor

\begin{tabular}{|l|l|l|l|l|l|}
\hline $\begin{array}{l}\text { Concentration } \\
(\mathrm{g} / \mathrm{L})\end{array}$ & $\begin{array}{l}\text { Corrosion } \\
\text { potential } \\
(\mathrm{mV})\end{array}$ & $\begin{array}{l}\text { Cathoidc } \\
\text { Tafel } \\
\text { slope } \\
(\mathrm{V} / \mathrm{dec})\end{array}$ & $\begin{array}{l}\text { Anodic } \\
\text { Tafel } \\
\text { slope } \\
(\mathrm{V} / \mathrm{dec})\end{array}$ & $\begin{array}{l}\text { Corrosion } \\
\text { current } \\
(\mathrm{A})\end{array}$ & $\begin{array}{l}\text { Protection } \\
\text { efficiency }\end{array}$ \\
\hline Blank & -478 & 5.792 & 7.183 & 0.006398 & \\
0.1 & -515 & 4.812 & 1.201 & 0.0004252 & 93.354 \\
0.2 & -515 & 4.761 & 1.236 & 0.0003993 & 93.758 \\
0.3 & -515 & 4.844 & 1.301 & 0.0003437 & 94.632 \\
0.4 & -516 & 4.857 & 1.023 & 0.0002965 & 95.365 \\
& & & & & \\
\hline
\end{tabular}




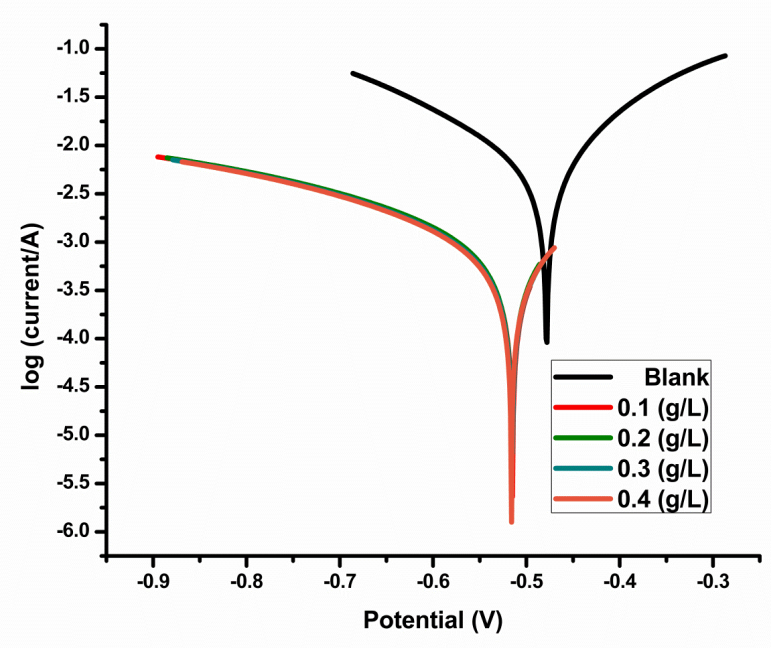

Figure 2. Tafel plots without and with inhibitor

\section{Impedance studies}

Figure 3 shows the Nyquist plots for MS in $3 \mathrm{M} \mathrm{HCl}$ solution without and with four different types of expired Abacavir Sulfate drug amounts $(0.1 \mathrm{~g} / \mathrm{L}, 0.2 \mathrm{~g} / \mathrm{L}, 0.3 \mathrm{~g} / \mathrm{L}$ and $0.4 \mathrm{~g} / \mathrm{L}$ of expired Abacavir Sulfate drug). The Nyquist plots are not perfect semicircle which is due to the MS surface heterogeneity. The charge transfer resistance and protection inhibition values obtained from the impedance studies are shown in the Table 4. From the Table 4, it is observed that, the charge transfer resistance values increases with a rise in the amounts of expired Abacavir Sulfate drug amount. The increase in the charge transfer resistance values with a rise in the expired Abacavir Sulfate drug is due to the adsorption of expired Abacavir Sulfate drug molecules on the MS surface in $3 \mathrm{M} \mathrm{HCl}$ solution. The phenomena of adsorption process enhances with an increase in the amounts of expired Abacavir Sulfate drug. Hence, protection efficiency increases with expired Abacavir Sulfate drug amounts.

Table 4. Impedance results of mild steel metal

\begin{tabular}{|l|c|c|}
\hline $\begin{array}{l}\text { Concentration } \\
(\mathrm{mg} / \mathrm{L})\end{array}$ & $\begin{array}{c}\text { Charge } \\
\text { transfer } \\
\text { resistance }(\Omega)\end{array}$ & $\begin{array}{l}\text { Protection } \\
\text { efficiency } \\
(\%)\end{array}$ \\
\hline Blank & 37.8 & 49.680 \\
2 & 75.12 & 69.318 \\
3 & 123.2 & 71.363 \\
4 & 132 & 72.648 \\
\hline
\end{tabular}




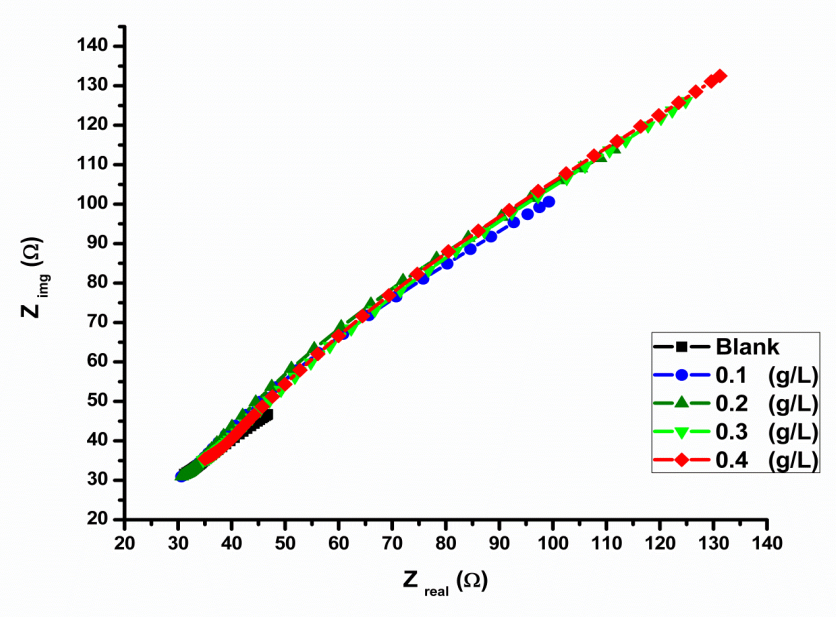

Figure 3. Impedance plots

The protection efficiency obtained from different techniques as shown in the Table 5 .

The different techniques and experimental condition are the main reason for the observed deviation in the protection efficiency values.

Table 5. Protection efficiency obtained from different techniques

\begin{tabular}{lll} 
Technique & $\begin{array}{l}\text { Optimum } \\
\text { concentration } \\
(\mathrm{g} / \mathrm{L})\end{array}$ & $\begin{array}{l}\text { Protection } \\
\text { efficiency }(\%)\end{array}$ \\
\hline $\begin{array}{l}\text { Weight loss } \\
\begin{array}{l}\text { Atomic } \\
\text { absorption } \\
\text { spectroscopy }\end{array}\end{array}$ & $0.4(\mathrm{~g} / \mathrm{L})$ & 95.000 \\
Tafel plots & $0.4(\mathrm{~g} / \mathrm{L})$ & 94.000 \\
& $0.4(\mathrm{~g} / \mathrm{L})$ & 95.365 \\
$\begin{array}{l}\text { Impedance } \\
\text { spectroscopy }\end{array}$ & & 72.648 \\
\hline
\end{tabular}

\subsection{Scanning Electron Microscopy (SEM) Technique}

The SEM images of MS surface in protected and unprotected condition as shown in the Figure $4(\mathrm{a}, \mathrm{b})$. From the SEM images, it is clear that, without expired Abacavir Sulfate drug, the MS surface is fully damaged and with expired Abacavir Sulfate drug of $0.4 \mathrm{~g} / \mathrm{L}$, the MS surface become smooth. The variation in MS surface morphology is due to adsorption of expired Abacavir Sulfate drug molecules on the electrode surface. The differences in the MS surfaces in without and with expired Abacavir Sulfate drug conditions are an indication of corrosion inhibition property of expired Abacavir Sulfate drug on the MS surface in 3 $\mathrm{M} \mathrm{HCl}$ solution. 

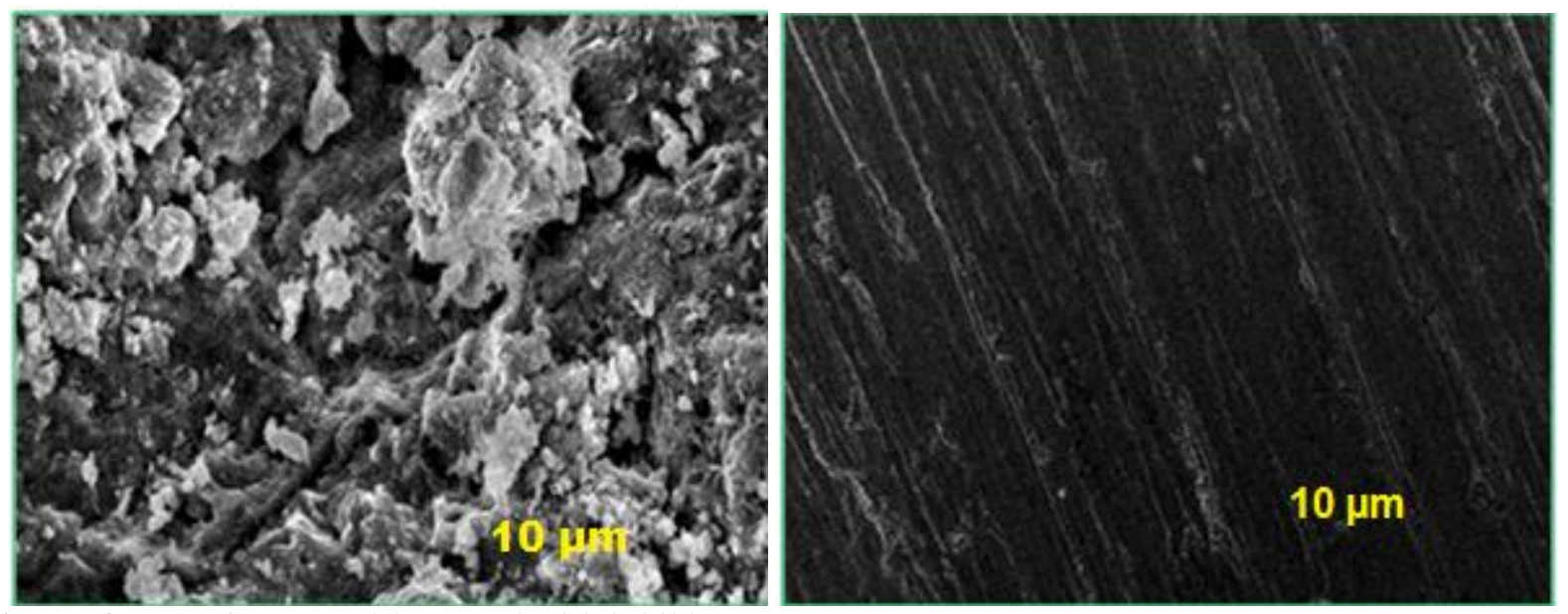

Figure 4. SEM images without and with inhibitor

\section{CONCLUSION}

Results obtained from the various techniques, weight loss, atomic absorption spectroscopy, Tafel plot, impedance, quantum chemical and scanning electron microscopy studies show that, nontoxic corrosion inhibition property of expired Abacavir Sulfate drug on the MS surface in $3 \mathrm{M} \mathrm{HCl}$ solution. All the studied technique shows that, corrosion protection property enhances with a rise in the expired Abacavir Sulfate drug concentrations. Tafel plot studies show that, expired drug A act a as mixed type of corrosion inhibitor on the MS surface in $3 \mathrm{M} \mathrm{HCl}$ solution. Impedance studies show that, highest charge transfer resistance value obtained at $0.4 \mathrm{~g} / \mathrm{L}$ of expired Abacavir Sulfate drug on the MS surface in $3 \mathrm{M} \mathrm{HCl}$ solution. SEM results support the weight loss, atomic absorption spectroscopy, Tafel plot, impedance methods.

\section{CONFLICT OF INTEREST}

No conflict of interest was declared by the authors.

\section{REFERENCES}

[1] Aljourani, J., Raeissi, K. and Golozar, M.A., "Benzimidazole and its derivatives as corrosion inhibitors for mild steel in $1 \mathrm{M} \mathrm{HCl}$ solution”, Corrosion Science, 51:1836-1843, (2009).

[2] Obot, I.B. and Obi-Egbedi, N.O., “ Anti-corrosive properties of xanthone on mild steel corrosion in sulphuric acid: experimental and theoretical investigations", Current Applied Physics, 11:382-392, (2011).

[3] Ahamad, I., Prasad, R. and Quraishi, M.A., "Thermodynamic, electrochemical and quantum chemical investigation of some schiff bases as corrosion inhibitors for mild steel in hydrochloric acid solutions", Corrosion Science, 52:933-942, (2010).

[4] Lebrini, M., Lagrenee, M., Vezin, H., Gengembre, L and Bentiss, F., "Electrochemical and quantum chemical studies of new thiadiazole derivatives adsorption on mild steel in normal hydrochloric acid medium", Corrosion Science, 47:485-505, (2005).

[5] Bahrami, M.J., Hosseini, S.M.A and Pilvar, P., "Experimental and theoretical investigation of organic compounds as inhibitors for mild steel corrosion in sulfuric acid medium", Corrosion Science, 52:2793-2803, (2010).

[6] Gunasekaran, G. and Chauhan, L.R., "Eco friendly inhibitor for corrosion inhibition of mild steel in phosphoric acid medium”, Electrochimica Acta, 49:4387-4395, (2004). 
[7] Eddy, N.O., Odoemelam, S.A. and Odiongenyi, A.O., "Joint effect of halides and ethanol extract of Lasianthera africana on inhibition of corrosion of mild steel in $\mathrm{H}_{2} \mathrm{SO}_{4}$," Journal of Applied Electrochemistry, 39:849-857, (2009).

[8] Ostovari, A., Hoseinieh, S.M., Peikari, M., Shadizadeh, S.R. and Hashemi, S.J. "Corrosion inhibition of mild steel in $1 \mathrm{M} \mathrm{HCl}$ solution by henna extract: a comparative study of the inhibition by henna and its constituents (lawsone, gallic acid, $\alpha$-D-glucose and tannic acid)," Corrosion Science, 5:1935-1949, (2009).

[9] Anupama, K.K., Shainy, K.M. and Joseph, A. "Excellent anticorrosion behavior of Ruta Graveolens extract (RGE) for mild steel in hydrochloric acid: electro analytical studies on the effect of time, temperature, and inhibitor concentration", Journal of Bio and Tribo Corrosion, 2:2 (2016).

[10] Oguzie, E.E., "Evaluation of the inhibitive effect of some plant extracts on the acid corrosion of mild steel", Corrosion Science, 50: 2993-2998, (2008). 